\title{
Benno Krieg
}

Chemie für Mediziner

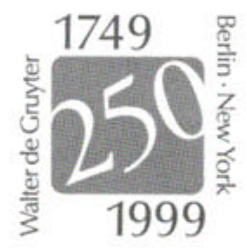



Benno Krieg

Chemie für Mediziner

Ein Lehr- und Übungsbuch

6., überarbeitete Auflage

W Walter de Gruyter

G Berlin - New York 1999 
Professor Dr. Benno Krieg

Institut für Organische Chemie

Freie Universität Berlin

Takustr. 3

14195 Berlin

Das Buch enthält 206 Abbildungen und 47 Tabellen

1. Auflage 1977

2. Auflage 1978

3. Auflage 1982

3. Auflage

Nachdruck, 1985

4. Auflage 1987

5. Auflage 1990

6. Auflage 1999

Die Deutsche Bibliothek - CIP-Einheitsaufnahme

Krieg, Benno:

Chemie für Mediziner : ein Lehr- und Übungsbuch / Benno Krieg. 6., überarb. Aufl. - Berlin ; New York : de Gruyter, 1999 ISBN 3-11-016425-6

(C) Copyright 1999 by Walter de Gruyter GmbH \& Co. KG, D-10785 Berlin.

Dieses Werk einschließlich aller seiner Teile ist urheberrechtlich geschützt. Jede Verwertung außerhalb der engen Grenzen des Urheberrechtsgesetzes ist ohne Zustimmung des Verlages unzulässig und strafbar. Das gilt insbesondere für Vervielfältigungen, Übersetzungen, Mikroverfilmungen und die Einspeicherung und Verarbeitung in elektronischen Systemen.

Printed in Germany

Einbandentwurf: Hansbernd Lindemann, Berlin

Satz: Werksatz Schmidt \& Schulz, Gräfenhainichen

Druck: Druckerei Gerike GmbH, Berlin - Bindearbeiten: Lüderitz + Bauer GmbH, Berlin 